\title{
Tripartite guanxi: resolving kin and non-kin discontinuities in Chinese connections
}

\author{
Jack Barbalet ${ }^{1,2}$ (D) \\ Published online: 20 June 2020 \\ (C) Springer Nature B.V. 2020
}

\begin{abstract}
A consensus holds that guanxi, understood as dyadic connections consolidated affectively and mobilized to achieve the purposes of members, exists in three forms (family guanxi, friendship guanxi, and acquaintance guanxi) distinguished by the strength of felt obligation between participants. It is also held that through practices of fictive kinship friendship guanxi may merge with family guanxi. This article challenges these propositions and the assumptions underlying them. Obligations of kinship and guanxi obligations are fundamentally dissimilar and the term "family guanxi" is redundant. Pseudo-family ties do not provide access to kin relations and their resources but instead affirm the distinction between family- and friendship-ties. Finally, because guanxi is cultivated by its participants, friendship guanxi and acquaintance guanxi are not distinct forms but rather are different possible stages of guanxi formation. The article goes on to consider the sources of these confusions, namely, common-language terms employed in sociological analysis, certain assumptions concerning Chinese culture, and finally methodological commitments that privilege latent structures of strong ties. The strength of guanxi ties, on the other hand, volitionally cultivated and indifferent to structural determination, fluctuates through agentic practices.
\end{abstract}

Keywords Acquaintance · Exchange-obligation · Friendship · Kinship · Particularistic instrumental ties $\cdot$ Role-obligation

Interpersonal connections are ubiquitous in all societies. In the context of Chinese society such connections are widely referred to as guanxi, a term generally understood to mean, among other things, a particularistic instrumental tie between persons who share an affective bond. Guanxi, understood in this latter sense, can be mobilized in

Jack Barbalet

jack.barbalet@acu.edu.au

1 Institute for Humanities and Social Sciences, Australian Catholic University, Locked Bag 4115 MDC, Fitzroy, Victoria 3065, Australia

2 Department of Social and Political Change, Australian National University, Canberra, Australia 
achievement of an extrinsic purpose that may include attainment of material or social resources, including access to another person's guanxi. We can date social science interest in guanxi from the late 1970s (Jacobs 1979), with sociological interest in particular accelerating from the late 1990s (Bian 1994; Gold et al. 2002; Lin 2001; Wank 1999). The application of sociological analysis to a characteristically Chinese form of relationship encourages refinement of both the analysis in question and sociological understanding of aspects of Chinese culture. The present article addresses a number of aspects of the treatment of guanxi in sociological and sociologicallyinformed accounts, the purpose of which is to clarify further the nature of guanxi and the scope of the term in its sociological apprehension.

While the discussion to follow focuses on an aspect of the sociology of contemporary China, the argument has general relevance. Indeed, since the global rise of China in the 1980s, guanxi as a basis of social capital has acquired a relevance that goes beyond China itself. In consideration of the varieties of capitalism, so-called "guanxi capitalism" has become a recognized form (Boisot and Child 1996; McNally 2011; Wang and Rowley 2017). Additionally, the account to follow, of principles underlying family guanxi, friendship guanxi, and acquaintance guanxi, relates to the prefixes of family, friendship, and acquaintance that are universally experienced and not confined to Chinese manifestations. The analysis presented here, then, while based in a treatment of guanxi, has general application and relevance.

The term guanxi, according to one author, has a "complicated and rich meaning" (King 1991, p. 68). Another writer, who does not necessarily disagree with this point of view, holds that the term "has lost its analytic usefulness, for it simultaneously refers to too many things and smooths over the distinctions in guanxi practice among the different identity categories" (Evasdottir 2004, p. 27). Such an acknowledgment, that guanxi is not a unified concept, is expounded by yet another writer who welcomes the idea that there "are different categories of guanxi, each with its own different behavioral and moral standards" (Luo 2011, p. 330).

The present article argues that if this last proposition is accepted then we shall have to agree that the term guanxi may indeed be without "analytic usefulness." Much that appears in current approaches to guanxi requires revision, as we shall see. But rather than disengage from using the term in analysis of social relationships in contemporary China, the treatment here takes current usage as a point of departure by both critically assessing how guanxi is understood and also by proposing alternate formulations. It is necessary to begin by considering a widely accepted view that there are three variant forms of guanxi, loosely described as family guanxi, friendship guanxi, and acquaintance guanxi (Bian 2018, pp. 603-604; Bian 2019, pp.142-147; Chen and Chen 2004, pp. 308-309; Fan 2002, pp. 551-553; Fu et al. 2006; Guo and Miller 2010; Hwang 1987; Luo 2011; Luo et al. 2016; Wank 1996, pp. 826-828; Yan 1996, pp. 99-100). I argue that the term "family guanxi" is redundant insofar as family connections constitute closed relations universally understood to entail implicit support between members on the basis of perceived need without expectation of a return provision. Additionally, this article argues that the distinction between friendship guanxi and acquaintance guanxi is best treated as indicating different phases of engagement rather than discrete categories of analysis, referring to dissimilar forms. Guanxi is shown here to be best conceived as a volitionally formed and therefore open relationship, without formal restriction on membership, encouraged by exchanges of various kinds. Another point at 
issue concerns a widely accepted idea that family guanxi and friendship guanxi are possibly linked through "pseudo-family" bonds. This assumption is also critically assessed below. This discussion clarifies a distinctive sociological statement of what constitutes guanxi.

\section{Family guanxi}

A hallmark proposition in the standard literature is that the strongest type and archetypical representation of guanxi is its family form, a guanxi based on ties of kinship (Bian 2019, pp. 2-11; King 1991, pp. 67-68, 75; Lin 2001, pp. 154-155; Luo 2011, pp. 332-333; Yang 1994, pp. 111-114). A defining characteristic of family guanxi is the provision of support in the absence of a favor in return. Such a relationship is based on what Hwang (1987) describes as the "needs rule," that one is obliged to assist a family member on the basis of their need, not in expectation of what they might do in return at some future time, as in the case of Hwang's "equity rule," nor on the basis of a quid pro quo of direct exchange, as with Hwang's "equality rule." Wank (1996, pp. 826-827) calls this "endowed" guanxi, that is "ascriptive and produced by birth" involving directly related kin (parents and offspring, brothers, and also possibly patrilineal cousins). He notes that it is "forthcoming with little or no need to offer material reward" because "intimacy can be more or less taken for granted" and there is therefore no need "to spend resources on deepening the ties" so that there is "a lack of explicit reciprocity ... [between] endowed ties" (Wank 1996, pp. 826, 828). There is a fundamental qualitative distinction between the obligations that obtain between close kin on the one hand and non-kin on the other. Guanxi obligations between the latter derive from exchanges that arise through shared experiences of friendship, through the provision of favors, or in recognition of a common interest facilitated through the exchange of gifts, which are what Wank (1996, pp 826-827) calls respectively "savings" guanxi and "investment" guanxi, corresponding with what this article descriptively calls "friendship guanxi" and "acquaintance guanxi." Although the terminology varies in different accounts, the general framework of what I describe here is more or less consistent in the literature.

The idea that kinship, between parents and offspring and also between siblings, is a sufficient basis from which instrumental support may be forthcoming, and therefore that a favor or gift is unnecessary between such kin in securing assistance, does not mean that family members do not exchange favors and gifts, as of course they may frequently do so. The point here, though, is that such exchanges are not the basis of support between family members whereas support between non-kin typically requires such favor exchange. The notion of family obligation without reference to guanxi has been found to be a continuing feature of social practice and commitment in China. The "structure of Chinese families continues to be one of mutual dependence rather than independence [and] economically, socially and emotionally Chinese family relationships tend to be close and inwardly directed" (Qi 2015, p. 151). While this pattern may be associated historically with Confucian norms, "from which it draws its imagery," its basis today is in the current structure of legal and administrative institutions and practices (Qi 2015, p. 157). As a result of the absence of alternative arrangements in China, including the provision by banks of start-up finance to small business, 
comprehensive state-provided aged care and other social goods, close family members are mainly the providers of such services and support. Under these circumstances, consistent reports of high levels of commitment to principles of family obligation are not surprising (Fuligni and Zhang 2004; Lin and Yi 2013; Whyte 2005).

Chinese rural-to-urban migrant workers who remit significant portions of their earning to immediate family demonstrate the strength of needs-based support between close kin. Internal migration in China is "underpinned by the pre-existing values of ... family loyalty" (Murphy 2002, p. 216; see also Guo et al. 2012). The purpose of migration in the vast majority of cases is to repatriate remittances to the family that stays behind, as remittances "represent one dimension of family ties and demonstrate high degrees of interaction between migrants and families at home" (Cai 2003, p. 472). Migrant workers will endure personal deprivation in order to increase the size of the remittance they send home (Huang and Zhan 2008, pp. 235-236). The vast majority of migrant workers remit; a widely accepted estimate is that approximately $75 \%$ of them do so. Those who do not remit typically have employers who withhold wages (Cheng et al. 2013), while a growing minority of migrant workers have no need to remit as they re-locate with family members (China Daily 2014; Hu et al. 2011; Qi 2018).

The sense of a needs-based family obligation is manifest in a concept of masculinity, "respectable manhood," developed by migrant workers in contrast to what they regard as the "moneyed manhood" of wealthy urban entrepreneurs (Choi and Peng 2016, pp. 100-101). Respectable manhood is "a sense of masculinity based on the effort a man makes to fulfill his responsibility to provide and care for his family" in contrast with "rich city entrepreneurs" who they regard as "corrupted by money" as well as prone to "marital infidelity" (Choi and Peng 2016, pp. 101-102). In light of this assessment, it is of particular interest that money-driven and adulterous entrepreneurs are themselves shown to adhere to the principle and practice of family obligation. In his ethnography of the new rich in the city of Chengdu, Osburg $(2013$, p. 67) shows that for these men "the domestic (jiali) was a realm of responsibility ... measured not by 'quality time' and fidelity, but by the conditions their families lived under." The importance of "responsibility (zerengan) to his family" remained a high value to these entrepreneurs (Osburg 2013, p. 72), just as it did for poor rural migrants who pride themselves as possessing "respectable manhood."

While there is agreement about the prevalence of support between family members, there are divergent views regarding its basis. In his classic treatment of the Chinese family, Fei (1992, pp. 73-75) holds that ethical norms govern relations among family members, in particular, the "ethical values" of "filial piety and fraternal duty" (Fei 1992, p. 74). This notion is echoed by Luo (2011, p. 331; Luo et al. 2016, p. 651) who holds that moral codes and family ethics secure the obligatory satisfaction of one family member's need by another. Other writers, though, have referred instead to emotions. Fan (2002, pp. 548-549) effectively distinguishes among the three types of guanxi indicated above in terms of three different emotions that "vary in both nature and intensity," namely "qinqing (affection to the loved ones), ganqing (emotion to friends) and renqing (human debt to acquaintances)." While the tripartite forms of guanxi may be considered to operate through three distinct emotions respectively, the particular emotions in question vary. Guo and Miller (2010, p. 274) write that the "core circle" of family guanxi is based "on ganqing (affection)-based guanxi ties" while an "intermediary circle" of non-kin ties is based on "renqing (reciprocity-based)" feelings and a 
"periphery circle" of non-kin is based on "jiaoqing (acquaintance-based) guanxi ties." The difference between Fan (2002) and Guo and Miller (2010) in relation to the emotional basis of family guanxi is interesting on two levels. First, qinqing simply means "family feeling," whereas ganqing, usually translated as affection or emotional commitment, has been widely regarded as the emotional basis of friendship (Fried 1953; Jacobs 1979; Smart 1999), although the term can also be used to describe affection between family members not in general but with regard to instances of affection between particular individuals. It is of particular interest, though, that Fei (1992, p. 88) explicitly rejects any role for ganqing in "stabilizing social relationships," preferring instead "understanding (liaojie)" of status mutuality and therefore distinction as essential in traditional kin relations. The linguistic shift reported here indicates how much Fei's analysis derives from possibly antiquated Confucian notions (see Barbalet 2020) and at the same time how in China today emotions tend to displace ethics in characterizing relationships.

The third term referred to by Guo and Miller above, jiaoqing, indicates feelings between acquaintances that emerge from contact between people and the exchanges in which they participate. In these terms, the feelings in question may not be the basis but rather the outcome of such contacts. Nevertheless, once it emerges, jiaoqing will consolidate a feeling of affection between friends who share a sense of pragmatic obligation (Chen and Chen 2004, p. 314; Guo and Miller 2010, p. 280). Finally, renqing is not particularly useful in distinguishing between the elements of tripartite guanxi because it can apply to any of them. Fei (1992, pp. 124-125) associates renqing with both family life and relations between friends and implies that it has customary and ritual dimensions (Fei 1992, pp. 126-127); indeed, one can take it to mean the etiquette of exchange. Renqing can also be understood as the emotions inherent in "natural" human relations, especially those of family life (Hwang 1987, p. 953; Yang 1994, p. 67). In addition, one can use the term to refer to feelings associated with appropriate action, including those emotions entailing a sense of proportionate expectation and the moral or normative patterns of social life and a person's sensibility to such norms. Renqing therefore also includes feelings associated with the provision of sympathy where it is appropriate, respect for others, acknowledging a favor, repaying a debt, and so on. These latter can be described as giving renqing (Hwang 1987, pp. 953954; Yang 1994, pp. 67-70). Renqing thus captures a broad spectrum of feelings concerning what is culturally appropriate for a given situation involving persons occupying particular roles. Failure to express appropriate emotions and to behave according to custom, propriety, and social etiquette is likely to lead to withdrawal of approval and therefore to loss of face (Hwang 1987, pp. 960-961; Yang 1994, p. 69). Renqing is thus an inadequate index of distinction among the three forms of guanxi indicated in the present discussion because it can be reasonably associated with any of them.

The purpose here is not to legislate on usage but to indicate the difficulty in providing simple rules for distinguishing the elements of tripartite guanxi on the basis of a culturally-informed emotions terminology. Any particular sense of obligation, including that underlying each of the distinct forms constituting tripartite guanxi, will have an ethical as well as an emotional element, one relating to its rationale, justification, or explanation and the other to its experiential manifestation. In a sociological discussion of family obligation in modern Britain both moral commitment and 
emotional feelings are indicated as necessary. The question of why close kin relations have power over individuals is explained sociologically by Finch (1994) in terms of a number of factors. First, a family of origin is the source of an "irrevocable membership" that "places each person in a series of two-way relationships with a number of individuals" (Finch 1994, p. 234), especially a parent, sibling, and offspring. These relationships are both socially visible and enduring, thus providing such irrevocable membership with special responsibilities that derive from "emotional ties and the history of relationships in which they are embedded" (Finch 1994, p. 235). Given the lifetime interaction between kin and its emotional significance to them, there is an inherent dynamic that reinforces "the social definition of kin as people whom you treat differently" (Finch 1994, p. 235). Another aspect of the lifelong interaction between kin noted by Finch is that kin relations have a "negotiated element" insofar as they operate as "a necessary mechanism for continually recreating and sustaining a sense of social identity" (Finch 1994, p. 235). Out of all of this, Finch (1994, p. 236) says, people form a "sense of the 'ideal norm' of kinship obligations," which provides them with an inescapable moral quality. The moral quality of kinship relations, Finch (1994, p. 236) goes on to add:

... can only be understood with reference to the sense which it enables people to make of their own position in the social world, rather than a fixed set of prescriptive rules which people follow. When it stops giving meaning and shape to the social world, the power of the moral imperative is reduced considerably, as it is when it conflicts with material self-interest.

These are important qualifications that explain both the compelling power of kinship over its participants and at the same time the possibility that the obligations "inherent" in kinship may in specified circumstances be ignored.

The moral imperatives of kinship within the framework of Confucian ethics are definitional, and therefore departure from them is more or less unconscionable within its ideological framework. This is a different perspective from the one provided by Finch, in which the idea of the moral quality of kinship corresponds to a means that "enables people to make [sense] of their own position in the social world, rather than a fixed set of prescriptive rules which people follow." The difference here, though, is between a philosophical outlook and a sociological, rather than between Chinese and Western understandings. In China as elsewhere, expectations of kinship may indeed be ignored and abrogated under certain circumstances. Possibly because of the strength of a culturally-based concept of the Chinese family, as both central and enduring, respondents who acknowledge a weakening of their sense of family obligation tend to qualify or downplay the reduction of its moral imperative, as in the case reported by Yang (1994, pp. 112-113) of a young woman whose feelings for her mother were "not very 'deep." In an unusually detailed account Chang (2010, pp. 385-390) provides summaries of a number of cases of family rupture in which kinship, at best, operates as a cleavage of hostility. Indeed, while kinship bonds are universally taken to imply an unconditional obligation of support for family members on the basis of need without regard to recompense, it is also universally acknowledged that the fulfillment of such obligations cannot be taken for granted. Fei (1992, p. 125) reports that family intimacy 
"may turn into resentment." A respondent reported by Guo and Miller (2010, p. 276), who held that communication with family members "does not always guarantee that you will get support from them," was not expressing a unique experience. Indeed, expected familial obligation cannot always be taken for granted (Guo and Miller 2010, p. 270; Fried 1953, pp. 91, 139-142).

To summarize this part of the discussion; family ties may lead to the provision of support between kin as the result of an obligatory sense based on irrevocable membership of a closed relation. A notable feature of this relationship is that support is provided between its constituents without requirement of recompense or acquisition of a debt. At the same time relations between family members may not necessarily meet the expectation implicit in this construction; as Finch indicates, it is always possible that the obligations of kinship may "stop giving meaning and shape to the social world" in which case "the power of [its] moral imperative is reduced considerably." In the present context, these two aspects of family obligation are taken as grounds for reassessing the idea that a guanxi relationship is involved in the case of family relations. The claim here is that the notion of guanxi is simply redundant in the case of family obligation because the family relationship itself is sufficient to characterize and explain the provision of support of one family member to another. There is no need to introduce an additional explanatory category that better serves in the characterization of non-kin obligatory relations as guanxi.

It must be noted that in the present context "kinship" refers to parent-child and sibling relations rather than to extended kinship. This qualification is important because the term "kinship" in the discussion of Chinese society, and guanxi in particular, is frequently used to refer to same-name lineage. This leads to a confusion that much of the discussion of guanxi has incorporated. In his classic account of the basis of Chinese society, Fei (1992, p. 74) says that the relations among family members, parents and children on the one hand and siblings on the other, are based on ethically informed obligations of filial piety and fraternal duty. He goes on to say, though, that "the unity of the intimate [kinship] group depends on the fact that each member owes countless favors to the other members" (Fei 1992, p. 124). It can be seen that Fei thus effectively invokes two distinct principles of organization, one pertaining to the immediate family and the other to extended kinship; these may be called respectively "role obligations" and "exchange obligations" (Barbalet 2020, pp. 15-17). Indeed, what distinguishes family relations from guanxi relations is that the former are closed to outsiders as they are based on obligations pertaining to life-long familial roles, as indicated above, whereas the latter is an open-ended relationship based on the obligations that arise from the exchange of favors.

Proponents of the notion of tripartite guanxi, which includes a family variant, will not necessarily disagree with the characterization of family-bonds presented here. Such agreement, however, does not lead to the conclusion the present discussion draws, because of a related assumption, which in effect covers over and ignores the difference between solidarity based on familial role obligations, on the one hand, and solidarity derived from the expectations of reciprocity based on exchange of favors, on the other. The assumption in question is that the closed relations of kinship and the open relations of friendship can be bridged and integrated through transitions in the latter to a "pseudo-family" form. It is therefore necessary to consider this issue. 


\section{Fictive kinship}

Corresponding with the supposition that the family is the primary institution of Chinese society, and a belief in the "inclusiveness" of Chinese kinship, much of the published discussion of guanxi assumes that non-kin social relationships may imitate the kinship form so that they become functionally equivalent to kinship and may merge with it in the constitution of family guanxi. According to Luo et al. (2016, p. 651), a "family tie" in the context of Chinese particularism includes "real- and pseudo-family ties" that maintain "loyalty ... unlimited ... [and] complete and unbreakable responsibility to each other." This statement echoes the supposition that persons construct guanxi out of either "kinship or fictive kinship bases" (King 1991, p. 68). Similarly Guo and Miller (2010, p. 270) hold that while family ties "are characterized by unconditional loyalty and involve social obligations that are not based on reciprocity ... people cannot solely rely on family in dealing with everyday life, and therefore, guanxi serves as a mechanism by which 'quasifamilial' relations can be created to cultivate trust among non-kin." In this way, they continue, "guanxi ties with non-kin can be viewed as an extension of guanxi ties inherent in family members." Such an argument is given a classical form through the Confucian notion of lun or cardinal relation, as when Luo (2011, p. 331) claims that "the concept of lun is not applied to only familial members ... [as the] five elements of Confucian lun also include loyalty between emperor and subordinates, and friendship." It does not follow, though, even though Luo and others assume that it does, that familial ties may therefore "include patron-client, adoptive, and blood-brother relations" because they take a "pseudo-familial" form (see also Bian 2018, p. 604; Chen and Chen 2004, pp. 307-308; King 1991, pp. 65-68).

Sociologically, the formation of fictive-kinship bonds can be understood in terms of two distinct processes, one is adoption of kinship terms of address between persons who do not share kin ties. This practice typically emerges out of a growing intensity of feelings that result from close and frequent interaction. Such interactions arise in structured circumstances or environments, as occurs among classmates, neighbors, workmates, or through the sharing of common interests, including recreational, vocational, or political interests. The other possibility, which generally requires this first as its precondition, is achieved through a ritualized ceremony that in the Chinese context is typically described as "sworn brotherhood" (jiebai xiongdi), a practice reported as early as the fourteenth century in the classic novels The Water Margin (Shuihu zhuan) attributed to Shi Naian and Romance of Three Kingdoms (Sanguo yanyi) by Luo Guanzhong. The discussion to follow examines sworn brotherhood first, followed by a treatment of the use of kinship terms of address between non-kin persons.

Bian (2019, p. 8) characterizes sworn brotherhood and other forms of "ritualized kin" as the "conversion of a non-kin tie into a kin tie through a ritualized ceremony" (see also Baker 1979, p. 164). While it is appropriate to describe sworn brotherhood as a form of fictive-kinship, it does not follow that a functional equivalent of a kin tie will emerge through it. This is because the "fictive quality" of sworn brotherhood "remains vibrantly in the consciousness of the participants, and no attempt is made to forget the artificiality of its creation" (Jordan 1985, p. 233). This latter point has been reinforced in a more recent discussion of a particular type of sworn brotherhood practiced in south China (Santos 2008). Santos argues that the practice of sworn brotherhood does not principally draw attention to the overarching significance of kinship in social life, but 
instead it paradoxically points to the importance of friendship. It is indicated that friendship is a "key form of human relatedness" consisting of alliances "marked by frequent voluntary displays of mutual generosity and trust with varying degrees of affection and practicality as well as instrumentality" (Santos 2008, pp. 536-537). We may find these qualities in kin relations, certainly, but friendship possesses them unencumbered by considerations of procreation or generational succession that more centrally define kinship. Indeed, friendship serves to provide a basis of non-kin alliance that is free of the competitive elements of Chinese kin relations, in which tensions between generations and laterally between siblings has been a traditional and also persisting feature of Chinese family life (Chang 2010, pp. 385-390; Freedman 1979, pp. 236-237; Newell 1985; Redding 1993, pp. 104-107, 215).

Unlike the compulsory bonds of kinship, the obligations of friendship are voluntary and therefore may be felt to be vulnerable to the demands and exigencies of kin. It is out of this circumstance that sworn brotherhood arises. Persons who deem friendship particularly significant may embark on the ceremonies of sworn brotherhood as a "way of protecting and reinforcing their relation of close friendship and allowing it to become longer-lasting" (Santos 2008, p. 543; see also Jordan 1985, pp. 233, 236-237). Indeed, Jordan (1985, pp. 238-239) shows that sworn brotherhood is a means of protecting close friendship from challenges by kin, so that sworn brothers may devote resources between themselves against the otherwise prior claims of kin, in this way "the kinship idiom in which [financial] assistance is phrased overcomes the argument that a person is helping his friend at the expense of his natural family, since his sworn brother may arguably constitute part of his family" (p. 238). Sworn brotherhood, then, draws on the kinship form as a means of defense against its obligatory demands. It indicates strengthened friendship, even though its ritualized form superficially suggests adoption of kinship protocols, which it effectively subverts. It is perhaps for this reason that Jacobs (1979, p. 249) sees sworn brotherhood as entirely secondary in considerations of guanxi even though it is widespread among his informants; its importance is "to symbolize an extant kuan-hsi (guanxi) which the parties wish to make closer."

In addition to ritualized kinship, "very close friends are likely to become pseudo-kin by addressing each other as brothers or sisters" (Bian 2019, p. 8). The role of "kinship addresses" (Yang 1994, p. 114) is widely considered to be responsible for the formation of fictive kinship or pseudo-family ties. It is assumed that "family-like sentiments" will emerge when participants "address each other in kinship terms, such as brothers, sisters, aunts and uncles" (Bian 2018, p. 604). Lin (2001, p. 154) argues that "the Chinese extend their relations beyond their families by constructing pseudofamilies" through the engagement of two types of social relationships. "First, there is a sharing of life experiences" so that:

... shared identities can be forged even if the two persons involved attended the same school or worked in the same unit years or decades apart. It is the intersection of individuals in the same social space that counts.

On this basis, the possibility of a second factor arises, namely such persons "may choose to make their relationship closer by calling each other 'old so and so' and eventually 'old brother' (laoxun) or 'old younger brother' (laodi)” and so on (Lin 2001, 
p. 154). Lin (2001, p. 155) is clear, though, that it is necessary to "differentiate these pseudo-relations from real familial relations" as they form parallel rather than integrated networks. However, the majority of scholars who discuss pseudo-familial relations tend to ignore this cautionary qualification. This article shows that these scholars overdraw even the weaker version of the pseudo-family argument on the basis of familial address-term usage.

Use of kinship terms of address has an obvious role in affecting the structure and depth of relations between addressee and addressor. In the Chinese context, strangers and acquaintances may use kinship terms in addressing each other as a means of indicating politeness, of generating familiarity or closeness, and inculcating a sense of intimacy. In polite exchanges, kinship terms are frequently invoked. It is reported that 'the kinship term a-sao ('sister-in-law') was used strategically by sales persons in privately owned stores in South China to claim familiarity with the customer as a way to show politeness and to persuade the customer" (Pan and Kádárb 2011, p. 1534). Indeed, the "use of such terms in address is mandatory for the closest relationships; it is preferable for medium-distance ones; and it is usable even with strangers, such as old women from whom one wishes to ask directions" (Blum 1997, p. 361). The use of kinship terms between persons who have no kin relationship is an extension outward of a kinship vocabulary rather than incorporation of persons into a kinship form of relation. The purpose is not to extend kinship but to achieve an extrinsic purpose, in Chinese "this is known as tao jinhu 'to try to win someone's friendship' or 'to butter someone up", (Wu 1990, pp. 86-87).

The use of kin terms between non-kin persons draws on a vocabulary significantly more limited than that used by kin. Chinese kinship terminology is extremely complex although it has become simpler in recent times. Drawing on classical sources Chen and Shryock (1932, pp. 631-638) identify 176 distinct kinship terms pertaining to father's clan, 16 terms used by the husband for his wife's clan (p. 639), 8 terms used by the wife for her husband's clan (p. 640) and 70 terms for mother's clan (pp. 640-643). Confining himself to mid-twentieth century usage Chao (1956, pp. 230-233) identifies a total of 114 distinct kinship terms. Wu (1990, pp. 66-67), on the other hand, in considering post-1978 reform China, indicates 10 distinct kinship terms relevant to father's family, 6 regarding mother's family, and 22 regarding one's own family. Approximately half of these terms "can be used to address non-kin although they have different distributions: some of them are used for strangers, some for acquaintances and some can be used for both situations ... [the different terms also distinguish] different degrees of familiarity in terms of the personal relations between speaker and addressee" (Wu 1990, p. 66). Although such usage is subject to certain linguistic restrictions, the employment of kinship terms to address non-kin is "one of the typical characteristics of Chinese [language]" that provides extensions of social familiarity between the parties of a conversational dyad, but does not provide access to the kin of the addressee (Wu 1990, pp. 62, 85):

The use of kinship address forms gives the impression of warmth and intimacy. This corresponds to the typical neighborhood situation in China. Neighbors help each other and treat each other as "family members." A Chinese proverb Yuanqin bu ru jinlin "Remote kin cannot compare with close neighbors" is a good 
indication of how Chinese people attach importance to the relationship among neighbors... By using kinship address forms, polite and close interpersonal relations can be established (Wu 1990, p. 86).

The idea that the use of kin terms between non-kin inculcates sociologically meaningful "fictive kinship" or "pseudo-family" ties requires careful qualification. As Wu (1990, p. 86) puts it: "By using kinship terms, for example in order to ask a favor of an addressee or to sell something to him/her, the speaker attempts to establish a temporary solidarity like that between family members."

The idea that the use of kin terms by non-kin may "establish a temporary solidarity like that between family members" has been taken by various writers to imply that the resulting fictive-kin or pseudo-family appellation bridges the gap between kin and nonkin and provides non-kin persons with access to the opportunities and resources associated with kinship. It has been shown here that this is not merely an exaggeration but it distorts the actual consequences of the use of kin address terms between non-kin individuals. In his classic study of the economic structure and social relations of Kaixiangong village in eastern China, Fei $(1939$, p. 90) notes that a limited range of kinship terms were used for addressing fellow villagers:

[The] purpose [of] this extended use of relationship terms ... [is to] attach certain psychological attitudes corresponding to the intimate relationships for which they were initially devised. These emotional attitudes may, by the extended use of the term, be taken up to persons not actually standing in such an intimate relationship.

Fei (1939, p. 91) goes on to say that:

... the extension of such emotional attitudes to persons not actually related as the terms would imply does not necessarily involve an extension of specific privileges and obligations. It does not imply a real extension of kinship relation.

This indicates not an incorporation of non-kin persons into relations between kin but on the contrary points to a clear disjuncture between authenticity and mimicry, effectively acknowledged by the tactical use of kin terminology.

\section{Friendship and acquaintance in guanxi}

In addition to the notion of "family guanxi," there is a broad consensus in the literature that there are two further types or forms of guanxi, descriptively identified above as "friendship guanxi" and "acquaintance guanxi." One can distinguish the terms of the particular configurations of obligation and sentiment that underlie each of them. In terms of the processes through which friendship and acquaintance operate, however, they can be described as different phases in a process of guanxi formation rather than as distinct and alternate kinds of guanxi. This is because there are no inhibiting factors that 
would prevent acquaintance developing into friendship or friendship weakening to mere acquaintance. On this basis, then, rather than as distinct types of guanxi, these may best be conceptualized as stages of guanxi formation.

Guanxi has been distinguished in terms of "the different types of people with whom the guanxi is formed" (Fu et al. 2006, p. 2). The distinction between "shuren (acquaintances or familiar persons such as neighbors, or people from the same village, friends, colleagues, or classmates) and shengren (strangers)," entails that one "type" of person may become another. This is because Fu et al. (2006, p. 5) argue that, as well as denoting strangers, "shengren also implies a yet-to-be-discovered guanxi created by common social identities shared by two parties," including a common birthplace, work place, educational institution, or a third person known to each of them. In this case, then, "shengren-based guanxi exists between two people who are connected by a yetto-be-discovered tie, such as a common social identity or a common third party ... [so that] two strangers (shengren) may establish a strong rapport as soon as they discover a common identity [or] shared values or interests after they meet and exchange information about each other.... the two could feel like old friends in a matter of minutes because of the obligations, expectations, as well as social norms, embedded in the newly-discovered tie" so that "shengren-based guanxi could change into a shurenbased relationship in a short time."

Note that the transformation of one type of guanxi into another may be in either direction, not only from shengren to shuren, but also from shuren to shengren, if one of the parties involved defaults on the relationship in some way (Fu et al. 2006, p. 7; see also Luo 2011, p. 345). These different stages of shengren, one existing prior to a transition to shuren and the other arising out of a spoiled shuren, are clearly not qualitative equivalents insofar as one indicates expansive potential while the other indicates contraction and loss of face (diu mianzi). But it is in the nature of guanxi that neither of these qualitatively distinct stages of shengren are final or terminal. Face may not only be lost, but lost face may be regained or recovered (Hwang 1987, pp. 961962; Qi 2017, pp. 9-10). Guanxi cultivation as an agentic engagement is necessarily multi-directional.

The distinction between friendship guanxi and acquaintance guanxi as well as the possibility of one converting to or merging with the other are widely accepted. This raises conceptual issues, though, that are seldom addressed. The first issue is that noncomparable qualities are used to identify each of these supposed forms of guanxi. Friendship guanxi is typically characterized in terms of the means employed in achieving it, such as identity markers of various kinds including an emotion. The particular emotion in question may vary; most frequently it is either ganqing (Fan 2002, p. 549; Fu et al. 2006, p. 7; Jacobs 1979, pp. 261-265; Kipnis 1997; Wank 1996, p. 826 ) or renqing (understood as feelings underlying proportionate relational expectation) (Hwang 1987; Luo 2011, pp. 331-332; Yan 1996). Acquaintance guanxi, on the other hand, is typically characterized not in terms of its means but its goal or purpose, whether that purpose is characterized as instrumental or as a debt-payment nexus, sometimes rendered as jiaoqing and — confusingly_renqing (understood as acknowledging a favor and repaying a debt) (Fu et al. 2006, p. 7; Guo and Miller 2010, pp. 280-281; Wank 1996, pp. 826-827). The basis of this use of non-comparable qualities in distinguishing friendship and acquaintance guanxi has its source in another distinction also frequently mentioned in discussion of guanxi, namely the distinction between 
expressivity, on the one hand, and instrumentality, on the other. If these are taken as alternatives, as they frequently are in discussion of guanxi (Gold 1985, p. 659; Hwang 1987, pp. 949-953; Yan 1996, pp. 226-229), then confusion will result. Expressivity and instrumentality are different but they are not alternatives; they co-exist in the practice of guanxi by each contributing to its possibility or occurrence (Barbalet 2015 , p. 1040). Even when the instrumental aspect is at a premium, as with business guanxi, favors can be exchanged only if there is expressivity realized as bonding feelings (ganqing) between participants (Osburg 2013, pp. 42-45).

A tripartite characterization of guanxi is further supported by a notion widespread among guanxi researchers that the discussion above has not yet treated directly, although implicit in much of that, is the necessity of guanxi bases in the formation of guanxi (Chen and Chen 2004, pp. 311-312; Chen et al. 2013, pp. 171-172; Jacobs 1979, pp. 243-256; Tong and Yong 1998; Yang 1994, pp. 111-119). Guanxi bases can be characterized in a number of ways, but they are essentially made of elements that correspond with the forms of guanxi commonly identified in the literature, including family and kinship and the various sources of friendship and acquaintance, including common locality or birthplace, education, employment, and so on. While guanxi bases are widely regarded as necessary in the formation of guanxi relations, they are typically not regarded as sufficient. In his classic statement concerning guanxi bases, Jacobs (1979) provides the qualification that the mobilization of any given guanxi base requires engagement of a particular "affective component," namely ganqing (sentimental attachment) that is achieved through "two dynamic processes: (1) social interaction and (2) utilization and helping" (Jacobs 1979, p. 259). Indeed, in his discussion of the political party activists that are the subject of his study, Jacobs shows that the level and type of activity in which they are engaged determines which guanxi base is relevant to their purposes and therefore which particular guanxi base they cultivate in establishing their relations with others. In this sense, then, guanxi bases are not determinative of guanxi relations and therefore do not produce guanxi in and of themselves. Rather, individuals select guanxi bases strategically to enable the formation of relations to achieve their purposes or intentions. The relationship, then, between a supposed guanxi base and the actual practice of guanxi may be entirely contingent, as discussion of guanxi bases indicates since Jacobs's seminal contribution.

Chen and Chen (2004, pp. 311-312) distinguish three types of guanxi bases: common social identity (of birthplace, educational institution, and workplace), triangular relations in which a third party links two otherwise unconnected persons, particularly useful for foreign business persons seeking a guanxi connection with a Chinese counterpart (see Luo 2007, pp. 159-209), and what they call an "anticipatory" base of future intention to form a guanxi relation:

In social and business interactions, individuals who do not share common social identification can still initiate a guanxi by creating potential future bases through expressing an intention or even a promise to engage in future exchanges, collaborations, or joint ventures. These guanxi intentions hence become guanxi bases for further interactions. Notice that potential guanxi partners often also share similar aspirations, ideals, or values but it is not similarity itself but the expressed intention of guanxi exchanges that constitute an anticipatory guanxi 
base (Chen and Chen 2004, pp. 311-312; see also Chen et al. 2013, pp. 172, 182).

The concept of an "anticipatory" guanxi base effectively indicates that the generic notion, "guanxi base," is in fact misleading. Rather than bases in the sense of something on which guanxi rests or that provides bottom-up support for guanxi practices, these elements are instead resources individuals may draw upon in creating a sense of common identity with another for their mutual benefit. If it is anything, a guanxi base is not a foundation or structural property but rather an opportunity for agentic engagement.

Guanxi always exists as a connection between individuals who cultivate it in order to achieve their purposes. Those purposes will necessarily be compounded, including securing and enhancing their social standing or face (mianzi) so that their reliability and therefore their availability for and appeal as prospective guanxi partners will be realized. As well as building their social resources, another purpose of a guanxi relation includes the mobilization of these resources to acquire materially beneficial goods or preferment in opportunities for acquiring such goods. The cultivation of guanxi requires a sense of shared identity or commonality of purpose that provides focus to the participants in cultivating their guanxi and also a sense of common commitment, achieved by emotional attachment to their association. Guanxi is not an emergent outcome of latent structures, then, that can be found in a pre-existing "base"; rather it is necessarily an open-ended relation that requires the time and resources to discover a (prospective) partner's tastes and purposes and how they may be matched to the initiator's own requirements and abilities in forging an enabling relationship that is guanxi. In terms of the qualities outlined here, guanxi is necessarily unlike the closed and compulsory relations of close kinship that form from a prior structure into which a person is born. A contact provided by either friendship or acquaintance may be recruited for the purpose of cultivating guanxi. Not all friendships and acquaintances will lead to a guanxi relationship, but no guanxi can be cultivated in the absence of such an initial social contact. Out of these contacts the persons involved cultivate a guanxi connection.

\section{Discussion}

As a category employed in social analysis, the term guanxi has an established presence and meaning, even though the content of that meaning operates in a wide penumbra because in many ways it remains sociologically unresolved. Nevertheless, it is possible to locate frequently sourced definitions in the literature that converge on some particular and arguably necessary characteristics. To confine ourselves to a small number of obvious cases (Bian 2006, p. 312; 2018, p. 603; 2019, p. 6; Chen and Chen 2004, p. 306; Gold 1985, p. 661; King 1991, p. 69) there is agreement that guanxi is an informal and particularistic dyadic connection, built or cultivated by the participants involved through a sense of common identity and sentiment, involving reciprocity and exchange generative of obligation, and with the potential of application to achieve purposive or instrumental outcomes. Beyond this summary account, agreement is difficult to locate. As indicated above, there is a broad consensus that a core form of guanxi exists 
between family members even though family guanxi is understood to occur in the absence of a requirement of exchange, based on a compulsion sufficient in itself to satisfy another's need. It is also widely assumed, as we have seen, that fictive-kinship or pseudo-family ties assimilate non-kin into family or family-like guanxi, even though firm evidence for such a prospect is absent. It has also been shown that the widespread conceptualization of distinct and separate guanxi forms based respectively on friendship and acquaintance can more meaningfully be characterized not as residual categories or states but rather as variable phases of non-kin relations. We can explain the confusion identified here in terms of three distinct factors of language, culture, and method. Each is considered in turn below.

Vernacular or everyday usage tolerates, indeed encourages, the idea that guanxi might apply to both kin and non-kin connections. The literal meaning of the term guanxi is much broader than the sociological renditions indicated above. Guanxi is a multiplex term that can refer to any type of relationship, not only between persons, and the quality of the relationship indicated is also variable. The first character, guan, means to close, shut or form a barrier, while the second character, $x i$, means to fasten or link as when systems or serial entities are formed. Together the characters indicate a relationship or a connection; that is all. The relationship in question may be causal, yinguo guanxi, or mathematical, shuxue guanxi; it may be a hostile relationship, didui guanxi, or a family relationship jiating guanxi. The relationship may be sexual, either innocent love, kending guanxi (literally, "to confirm the relationship"), or an illicit relationship, luan gao nannu guanxi (literally, "disorderly relations between a man and a woman"). "Guanxi" may also refer to an evaluative relationship, as in meiyou guanxi (literally, "not having concern") indicating that something "does not matter." It also, of course, may mean a social relationship, shehui guanxi. It goes without saying that social relationships may be of many types. As indicated above, the type that is implied in the social science discussion of guanxi is generally a dyadic relation, based on sentiment or affection and involving exchanges of favor or reciprocal benefit. When people in conversation refer to guanxi, they may not necessarily have any one of these particular meaning in mind, but some other; and if they do refer to the type of relationship discussed in social science treatments of guanxi they may use a term other than guanxi, such as renmai (literally, "human mountain range" or "vascular system," indicating expansive connections), referring to sustaining contacts or networks, or goudui, literally "blend," implying relationship cultivation, or some other construction.

By its nature, sociological discussion inevitably draws on everyday terms, namely categories based on direct experience of social participation that are used to refer to such experiences of participation by those involved. This is not to suggest that sociology is devoid of technical terms, but in treating aspects of relationships and social organization the words that social participants themselves employ frequently inform more formal characterizations of events and processes and thus effectively play a dual role, as vernacular labels and also technical terms. Recognition of the problematic nature of this dual aspect of natural language words in sociological discourse is not new. It has, however, not led to acknowledgment of limitations in the social science discussion of guanxi, let alone attempts to rectify such problems. The caution indicated by Merton (1968, pp. 145, 168-169), that sociological explanation requires not only empirical investigation but also "conceptual analysis" and conceptual "clarification," can be applied to how the vernacular concept of guanxi is sociologically employed. 
Concepts "constitute the definitions (or prescriptions) of what is to be observed; they are the variables between which empirical relationships are to be sought" so that the "function of conceptual analysis ... is to maximize the likelihood of the comparability ... of data which are to be included in the research" (Merton 1968, pp. 143, 145).

When the same common-language term, guanxi, is applied to both close family-or kin-connections and non-kin connections that provide support to participants, even though one is based on closed relations not requiring a return favor and the other on open relations in which such return favors are routine and necessary, then the comparability of data will be jeopardized. In such situations the discussion is rationalized in ways that led Stinchcombe (1968, p. 41), for instance, to say that when "natural variables" are seen to have "multiple causes," then the "researcher is trying to explain the wrong thing." More recently it has been acknowledged that "If the everyday meaning is used, the research will have difficulty in creating a sociological analysis and may instead end up with one that is based on folk wisdom" (Swedberg 2019, p. 5). This is a situation that arguably emerges when it is supposed that guanxi derives its meaning from a supposed Confucian basis of Chinese society.

It is held to be axiomatic in a significant section of the guanxi literature that China is a "Confucian society" (Bian 2019, pp. 9-12; Fu et al. 2006, p. 17; Guo and Miller 2010 , p. 270; Wang and Rowley 2017, pp. 102-104), a view encouraged by official and semi-official sources since the 1980s (Makeham 2008) and given explicit sociological endorsement (Kang 2013). But this proposition requires careful examination. The ideological dominance of Confucianism was attempted after the Hundred Days Reform (Wuxu Bianfa) of 1898 when, in an endeavor to preserve the Qing court during a period of political, economic, and military turmoil, Confucian literati sponsored the suppression of Buddhism, Daoism, and local cults, newly designated as "superstitions" (Goossaert 2006). This was in contravention of the established view, that had operated from the sixth century, that Chinese culture is based on the harmonious combination of "three teachings" (san jiao), namely Confucianism, Daoism, and Buddhism, which together inform Chinese cultural and social practices and orientations. In the last decades of imperial China a population of approximately 400,000,000 people was governed by "not more than 40,000 officials" (Michael 1955, p. 420). These officials were the literati who attained office on the basis of their success in examinations that certified their knowledge of the Confucian classics. Not all degree holders were officials; by the end of the nineteenth century there were approximately $1,500,000$ degree-holders in China, known collectively as the gentry (shenshi); together with their families, this group - gentry and their family members - comprised up to 7.5 million individuals, just over 2\% of the population (Michael 1955, p. 422; Yang 1959, p. 255; see also Stover 1974). In this sense, the social bearers of Confucianism constituted a tiny proportion of the Chinese people. The vast majority of the population, peasants excluded from both governance and privilege, had little knowledge of or interest in Confucianism. With the collapse of the Qing Dynasty through the advent of Republican China in 1911, Confucianism was itself disembedded from its social and political base.

In reaction to the anti-traditional New Culture Movement (1913-1917), conservative scholars and gentry elements during the period from the 1920s until the late-1940s attempted to reassert Confucian social doctrine (Chow 1960, pp. 329-332). A leading late-Republican Confucian thinker, Liang Shuming, was an unacknowledged influenced on Fei Xiaotong (Arkush 1981, p. 150; Gransow 2001, p. 268; Lu and Zhao 
2009, p. 55) whose work Xiangtu Zhongguo, first published in 1947 (Fei 1992), has informed the theoretical framework of many guanxi studies. Indeed, late-Republican Confucianism was the source of the idea that the "most important relationship" in Chinese society is kinship (Fei 1992, p. 63) and that the Chinese family as lineage has a permanency and structural flexibility that the merely conjugal family lacks and therefore that the "Chinese family is a medium through which all activities are organized" (Fei 1992, p. 84). These ideas underpin the conception of guanxi expressed in leading sections of the sociological literature (e.g., Bian 2019, pp. 213-218; King 1991; for an alternative appreciation of Fei's contribution, see Barbalet 2020).

The presentation of the Chinese family briefly indicated above was subject to significant sociological critique during the late-Republican period (Cheng 1939; Hsu 1943; Lee 1949). Indeed, on the basis of fieldwork in Sichuan in the late 1940s Skinner (1964, p. 32) shows that "anthropological work on Chinese society, by focusing attention almost exclusively on the village, has with few exceptions distorted the reality of rural social structure," a limitation for which Fei has been criticized (Chun 2012, p. 264; Freedman 1979, pp. 389-390; Wang 2012, p. 180). In particular Skinner (1964, pp. 35-39) shows that the networks of Chinese rural society were by no means confined to relations between village-based kin but involved extensive and important connections among non-kin. Similarly, on the basis of extensive fieldwork carried out during 1947-48 in Zhu Xian within Anhui Province, Morton Fried (1953, p. 230) shows that the "complex design of Chinese society becomes more comprehensible when systematic study of extra-familial relations is added to the research on Chinese familial organization." Fried's study shows that the structure of relations is not exhausted by kinship and that other forms of relationships, summarized in large part as non-kin friendship, operate alongside kinship. Friendship, Fried (1953, p. 67) says, "at times ... serves as a complement to pre-existing kinship rights and obligations [though] it often challenges kinship for prior loyalty ... [when it] furnishes avenues by which familial pressures may be avoided and introduces elements which are potentially subversive of familial unity" (see also pp. 218, 230). Fried insists, therefore, that a comprehensive and meaningful understanding of Chinese society, both rural and urban, requires that due regard is given to non-kin relationships in their own right. Second, he identifies an independent basis of non-kin relations in ganqing, prefiguring the later treatment of guanxi. This important corrective to the revivalist Confucianism of Fei (1992) and others is overlooked or simply misunderstood, as when Bian (2001, p. 276) claims that:

Fried's study of a county seat in Anhui province before 1949 confirms that the web of familial and kinship obligations indeed extended into and became the "fabric" of the economic, political and social organizations of the county seat before the 1949 Communist revolution.

Fried (1953) in fact shows the opposite. The point here does not suggest that kinship is without importance in Chinese society but rather that the Confucian ideological elevation of kinship as both socially dominant and an archetypical form to which other types of relations are subject is not supported by the evidence. 
Finally, a tripartite guanxi formation with family guanxi at its core tends to be a favored conceptualization when Social Network Analysis (SNA) is chosen as the method for data-gathering and explanation. This is because tie strength enjoys explanatory privilege in SNA. It is not possible here to develop a full argument concerning departures of guanxi networks from the network form assumed by SNA, which is provided elsewhere (Barbalet 2015). In the present context, it is sufficient to show that difficulties for the study of guanxi become apparent when tie-strength is the basis of analysis, as indicated in the following account:

... a friend should be categorized as a weak tie if the definition follows the kinship method, but the job seeker may have frequent interactions with this friend and they may share many homogenous personal characteristics. Hence, there is a strong relationship between the job seeker and the friend, and this so-called weak tie can be much stronger than a strong tie relative with whom the job seeker has infrequent contact (Weng and Xu 2018, p. 72).

Consideration concerning guanxi, as this quotation implicitly indicated, signifies that through guanxi weak ties become strong ties and strong ties may become weak. The observation that the "art of guanxi involves the strategic strengthening of weak into strong ties" may encourage the idea "that weak and strong ties are not permanently distinct categories" (Smart 1998, p. 561). More importantly it might lead to a questioning of why these categories are used at all in attempts to understanding guanxi, and how guanxi connections may be more adequately theorized. As a cultivated practice the predictors of guanxi cannot be social ties embedded in latent structures. Guanxi comprises agentic practices volitionally constructed or created by the participants in their interaction and the ties between participants are therefore never fixed. It is necessary, then, to distinguish a guanxi connection from a network tie ( $\mathrm{Wu}$ and Wall 2019). The construction of guanxi connections requires mutual long-term monitoring and surveillance as well as personal disclosure and shared activities of various sorts, as described by ethnographic accounts (e.g., Osburg 2013; Wank 2009). The strength of any guanxi connection is always and necessarily a work in progress, never final and always capable of being increased as well as decreased through the activities of those involved.

\section{Conclusion}

Guanxi is a form of particularistic tie integral to social connections based on affective bonds generated or maintained by favor exchange and mobilized in order to achieve the purposes of its participants. The study of guanxi has attracted growing attention in the social sciences since the early 1980s. While research on guanxi was originally conducted primarily by anthropologists and sociologists, today the largest single research constituency focused on guanxi is business and marketing academics (Liu and Mei 2015). Researchers, who favor a tripartite model of guanxi as discussed in the present article, are drawn from the full range of social science disciplines. This testifies to the 
broadness of the appeal of the idea that family guanxi, friendship guanxi, and acquaintance guanxi are distinct forms of guanxi subject to different types of obligation.

If the study of guanxi is to continue to act as a platform that provides meaningful knowledge of social relations in Chinese society, then conceptual refinement and increased theoretical sophistication are required. Such a task inevitably includes challenging those assumptions that underlie current research and examining suppositions inherent in established linguistic practices and cultural beliefs that are not the foundation of social scientific refinement but its impediment. The issue here is not entirely the one Lewis Carroll captured, in Through the Looking-Glass, by a conversation between Humpty Dumpty, an anthropomorphic egg, and Alice, a young girl who visits an impossible world:

"When $I$ use a word," Humpty Dumpty said, in rather a scornful tone, "it means just what I choose it to mean-neither more nor less."

"The question is," said Alice, "whether you can make words mean so many different things."

"The question is," said Humpty Dumpty, "which is to be master- that's all."

The meaning of terms in arguments concerning guanxi does not necessarily reflect the arbitrary power of a Humpty Dumpty. The case under consideration highlights instead the risks in the acquiescence of social scientists to the overarching influence of everyday language, cultural stereotypes, and inappropriate or limited methods. These conventional powers, rather than the power of persons, over-determine the ways in which guanxi is understood in the social science literature. Theoretically robust research can proceed only on the basis of conceptual refinement. The contribution of the present article is to show that the notion of guanxi is in need of such refinement. A way in which the conceptual refinement of guanxi in sociological treatments may be achieved is also indicated in the article.

In particular, it has been shown that if the widely accepted core notion of guanxi as a "personalized tie between two persons affectively connected and engaged in an exchange of favors" is taken as basic, then a number of things follow. First, the obligations of reciprocity that derive from guanxi exchanges must be distinguished from the role obligations that typically underpin the support provided by a parent to a child, for instance, by a child to a parent, and between siblings. This distinction in forms of obligation is fundamental, as indicated in the difference between "a social structure of positions in relation" and a "social structure of relations among persons" (Coleman 1990, pp. 427428). In the first of these, Coleman goes on to say, persons "take on the obligations and expectations ... associated with their positions," whereas in the second the obligations arise out of mutually beneficial transactions that exist in exchanges as "self-contained pairwise relations." Discussion above showed how these distinct bases of relations, one associated with the closed affinities of immediate family and the other with the open possibilities of non-kin acquisitions of esteem, social standing, or face through a voluntary provision 
appreciated by another (Blau 2017; Brennan and Pettit 2004), are obscured when family or kin relations are defined broadly and also taken to incorporate non-family members through the means of fictive kinship.

A second thing that follows from the core statement of guanxi indicated above, then, is that one cannot take for granted or at face value assumptions related to the mechanisms of sworn brotherhood and the use of familial names in bridging kin and non-kin ties. As we explained earlier, the practices of fictive kinship encourage a sense of psychological closeness without providing access to the resources of kinship, in the case of the use of familial names, and also that sworn brotherhood in fact intensifies friendship bonds by adopting familial forms in order to protect participants from the intrusive demands of kinship that may detract from a friendship connection. Both of these findings encourage the view that the basic content of guanxi connections derive from the friendship form rather than the kinship form. This is a conclusion quite contrary to the dominant understanding in the current literature. Finally, we have seen that the distinction between friendship guanxi and acquaintance guanxi is phasal rather than definitive. By its nature, guanxi is both open in the possibilities of membership or association and flexible in its operation, subject to the intention of its participants and the utility of its provision, both of which are context-given and subject to volitionally driven change and variation. In this sense, then, acquaintance and friendship as proxy terms for guanxi episodes are each ever likely to be variably dominant, and therefore variably recessive, depending on the changing needs, resources, and broader situation of participants.

This discussion also establishes that inhibition on attaining the findings it summarizes can be readily understood as derived from an over-reliance on everyday terms in sociological analysis, acceptance rather than critical assessment of cultural assumptions in social reasoning, and insufficient reflexivity in adoption of research methods. Advances in the sociological study of guanxi have been cumulative over the past thirty years. At the same time, the practices of guanxi have changed as the society to which they are attached changes, and the transformation of China since the onset of economic marketization in the early 1980s has been unprecedented. The present article contributes to the continuing reflections on guanxi by applying systematic sociological analysis to certain widely held assumptions in the sociology of China, in order to increase appreciation of the nature of guanxi and the distinctions within it.

Funding This study has received no funding.

\section{Compliance with ethical standards}

Conflict of interest The author declares that he has no conflict of interest.

\section{References}

Arkush, R. D. (1981). Fei Xiaotong and sociology in revolutionary China. Cambridge, MA: Harvard University Press.

Baker, H. D. R. (1979). Chinese family and kinship. New York: Columbia University Press. 
Barbalet, J. (2015). Guanxi, tie strength, and network attributes. American Behavioral Scientist, 59(8), 10381050.

Barbalet, J. (2020). The analysis of Chinese rural society: Fei Xiaotong revisited. Modern China, OnlineFirst, (16 January), 009770041989492. https://doi.org/10.1177/0097700419894921.

Bian, Y. (1994). Guanxi and the allocation of urban jobs in China. The China Quarterly, 140, 971-999.

Bian, Y. (2001). Guanxi capital and social eating in Chinese cities. In N. Lin, K. Cook, \& R. S. Burt (Eds.), Social capital: Theory and research (pp. 275-295). New Brunswick, NJ: Transaction.

Bian, Y. (2006). Guanxi. In J. Beckert \& M. Zafirovski (Eds.), International encyclopedia of economic sociology (pp. 312-314). London: Routledge.

Bian, Y. (2018). The prevalence and the increasing significance of guanxi. The China Quarterly, 235, 597621.

Bian, Y. (2019). Guanxi: How China works. Cambridge: Polity Press.

Blau, P. M. (2017). Exchange and power in social life (new ed.). London: Routledge.

Blum, S. D. (1997). Naming practices and the power of words in China. Language in Society, 26(3), 357-379.

Boisot, M., \& Child, J. (1996). From fiefs to clans to network capitalism: Explaining China's emerging economic order. Administrative Science Quarterly, 41(4), 600-628.

Brennan, G., \& Pettit, P. (2004). The economy of esteem: An essay on civil and political society. Oxford: Oxford University Press.

Cai, Q. (2003). Migrant remittances and family ties: A case study in China. International Journal of Population Geography, 9(6), 471-483.

Chang, X. (2010). Guanxi or lishang wanglai? Reciprocity, social support networks and social creativity in a Chinese village. Taipei, Taiwan: Airiti Press.

Chao, Y. R. (1956). Chinese terms of address. Language, 32(1), 217-241.

Chen, C. C., Chen, X.-P., \& Huang, S. (2013). Chinese guanxi: An integrative review and directions for future research. Management and Organization Review, 9(1), 167-207.

Chen, T. S., \& Shryock, J. K. (1932). Chinese relationship terms. American Anthropologist, New Series, 34(4), 623-664.

Chen, X-P., \& Chen, C. C. (2004). On the intricacies of the Chinese guanxi: A process model of guanxi development. Asia Pacific Journal of Management, 21(3), 305-324.

Cheng, C.-K. (1939). The Chinese large family system and its disorganization. Social Forces, 17(4), 538-545.

Cheng, Z., Nielsen, I., \& Smyth, R. (2013). Determinants of wage arrears and their implications for the socioeconomic wellbeing of China's migrant workers, Department of Economics Discussion Paper 50/ 13. Monash University.

China Daily (2014). Summary of China's migrant population report for 2013. China Daily, 16 May. Available at: www.chinadaily.com.cn/m/chinahealth/2014-05/16/content 17514058 .htm.

Choi, S. Y. P., \& Peng, Y. (2016). Masculine compromise: Migration, family and gender in China. Oakland, CA: University of California Press.

Chow, T.-t. (1960). The may fourth movement: Intellectual revolution in modern China. Cambridge, MA: Harvard University Press.

Chun, A. (2012). From sinicization to indigenization in the social sciences. In A. Dirlik, G. Li, \& H.-P. Yen (Eds.), Sociology and anthropology in twentieth-century China (pp. 255-282). Hong Kong: Chinese University Press.

Coleman, J. S. (1990). Foundations of social theory. Cambridge, MA: Harvard University Press.

Evasdottir, E. E. S. (2004). Obedient autonomy: Chinese intellectuals and the achievement of orderly life. Honolulu, HI: University of Hawai'i Press.

Fan, Y. (2002). Questioning guanxi: Definition, classification and implications. International Business Review, 11(5), 543-561.

Fei, H. T. (1939). Peasant life in China: A field study of county life in the Yangtze valley. London: Routledge and Kegan Paul.

Fei, X. (1992). From the soil: The foundations of Chinese society. Berkeley, CA: University of California Press.

Finch, J. (1994). Family obligations and social change. Cambridge: Polity.

Freedman, M. (1979). The study of Chinese society. Stanford, CA: Stanford University Press.

Fried, M. H. (1953). Fabric of Chinese society: A study of the social life of a Chinese county seat. New York: Praeger.

Fu, P. P., Tsui, A. S., \& Dess, G. G. (2006). The dynamics of guanxi in Chinese hightech firms: Implications for knowledge management and decision making. Management International Review, 46(3), 1-29.

Fuligni, A. J., \& Zhang, W. (2004). Attitudes toward family obligation among adolescents in contemporary urban and rural China. Child Development, 74(1), 180-192. 
Gold, T. B. (1985). After comradeship: Personal relations in China since the cultural revolution. The China Quarterly, 104, 657-675.

Gold, T., Guthrie, D., \& Wank, D. (Eds.). (2002). Social connections in China: Institutions, culture and the changing nature of guanxi. Cambridge: Cambridge University Press.

Goossaert, V. (2006). 1898: The beginning of the end for Chinese religion. Journal of Asian Studies, 65(2), 307-336.

Gransow, B. (2001). "Nontranslatable:" indigenous concepts in social science research on China. Asian Journal of Social Science, 29(1), 262-284.

Guo, C., \& Miller, J. K. (2010). Guanxi dynamics and entrepreneurial firm creation and development in China. Management and Organization Review, 6(2), 267-291.

Guo, M., Chi, I., \& Silverstein, M. (2012). The structure of intergenerational relations in rural China: A latent class analysis. Journal of Marriage and Family, 74(5), 1114-1128.

Hsu, F. L.-K. (1943). The myth of Chinese family size. American Journal of Sociology, 48(5), 555-562.

Hu, F., Xu, Z., \& Chen, Y. (2011). Circular migration, or permanent stay? Evidence from China's rural-urban migration. China Economic Review, 22(1), 64-74.

Huang, P., \& Zhan, S. (2008). Migrant workers' remittances and rural development in China. In J. DeWind \& J. Holdaway (Eds.), Migration and development within and across borders (pp. 221-245). New York: Social Science Research Council.

Hwang, K.-k. (1987). Face and favor: The Chinese power game. American Journal of Sociology, $92(4), 944$ 974.

Jacobs, J. B. (1979). A preliminary model of particularistic ties in Chinese political alliances: Kan-ch'ing and kuan-hsi in a rural Taiwanese township. The China Quarterly, 78, 237-273.

Jordan, D. K. (1985). Sworn brothers: A study in Chinese ritual kinship. In J.-C. Hsieh \& Y.-C. Chuang (Eds.), The Chinese family and its ritual behavior (pp. 232-262). Taipei: Institute of Ethnology, Academia Sinica.

Kang, X. (2013). Confucianism and conceiving a cultural renaissance in the new century. Contemporary Chinese Thought, 44(2), 61-75.

King, A. Y.-c. (1991). Kuan-hsi and network building: A sociological interpretation. Daedalus, 120(2), 6384.

Kipnis, A. B. (1997). Producing guanxi: Sentiment, self, and subculture in a North China village. Durham, NC: Duke University Press.

Lee, R. H. (1949). Research on the Chinese family. American Journal of Sociology, 54(6), 497-504.

Lin, J.-P., \& Yi, C.-C. (2013). A comparative analysis of intergenerational relations in East Asia. International Sociology, 28(3), 297-315.

Lin, N. (2001). Guanxi: A conceptual analysis. In A. Y. So, N. Lin, \& D. Poston (Eds.), The Chinese triangle of mainland China, Taiwan, and Hong Kong: Comparative institutional analysis (pp. 153-166). Westport, CT: Greenwood Press.

Liu, L., \& Mei, S. (2015). How can an indigenous concept enter the international academic circle: The case of guanxi. Scientometrics, 105(1), 645-663.

Lu, W., \& Zhao, X. (2009). Liang Shuming's viewpoint of Chinese and Western cultures in The substance of Chinese culture. Contemporary Chinese Thought, 40(3), 52-66.

Luo, J.-D. (2011). Guanxi revisited: An exploratory study of familiar ties in a Chinese workplace. Management and Organization Review, 7(2), 329-351.

Luo, J.-D., Cheng, M.-Y., \& Zhang, T. (2016). Guanxi circle and organizational citizenship behavior: Context of a Chinese workplace. Asia Pacific Journal of Management, 33(3), 649-671.

Luo, Y. (2007). Guanxi and business. Singapore: World Scientific.

McNally, N. (2011). China's changing guanxi capitalism: Private entrepreneurs between Leninist control and relentless accumulation. Business and Politics, 13(2), 1-29.

Makeham, J. (2008). Lost soul: "Confucianism" in contemporary Chinese academic discourse. Cambridge, MA: Harvard University Press.

Merton, R. K. (1968). Social theory and social structure (enlarged ed.). New York: The Free Press.

Michael, F. (1955). State and society in nineteenth-century China. World Politics, 7(3), 419-433.

Murphy, R. (2002). How migrant labor is changing rural China. Cambridge: Cambridge University Press.

Newell, W. H. (1985). Structural conflicts within the Chinese family. In J.-C. Hsieh \& Y.-C. Chuang (Eds.), The Chinese family and its ritual behavior (pp. 84-93). Taipei: Institute of Ethnology, Academia Sinica.

Osburg, J. (2013). Anxious wealth: Money and morality among China's new rich. Stanford, CA: Stanford University Press.

Pan, Y., \& Kádárb, D. Z. (2011). Historical vs. contemporary Chinese linguistic politeness. Journal of Pragmatics, 43(6), 1525-1539. 
Qi, X. (2015). Filial obligation in contemporary China: Evolution of the culture-system. Journal for the Theory of Social Behaviour, 45(1), 141-161.

Qi, X. (2017). Reconstructing the concept of face in cultural sociology: In Goffman's footsteps, following the Chinese case. Journal of Chinese Sociology, 4(19), 1-17.

Qi, X. (2018). Floating grandparents: Rethinking family obligation and intergenerational support. International Sociology, 33(6), 761-777.

Redding, S. G. (1993). The spirit of Chinese capitalism. Berlin: de Gruyter.

Santos, G. D. (2008). On "same-year siblings" in rural South China. Journal of the Royal Anthropological Institute, 14(3), 535-553.

Skinner, G. W. (1964). Marketing and social structure in rural China: Part I. Journal of Asian Studies, 24(1), $3-43$.

Smart, A. (1998). Guanxi, gifts and learning from China: A review essay. Anthropos, 93(4/6), 559-565.

Smart, A. (1999). Expressions of interest: Friendship and guanxi in Chinese societies. In S. Bell \& S. Coleman (Eds.), The anthropology of friendship (pp. 119-136). Oxford: Berg.

Stinchcombe, A. L. (1968). Constructing social theories. New York: Harcourt, Brace and World.

Stover, L. E. (1974). The cultural ecology of Chinese civilization: Peasants and elite in the last of the agrarian states. New York: Pica Press.

Swedberg, R. (2019). On the use of definitions in sociology. European Journal of Social Theory, Online First, March., 136843101983185. https://doi.org/10.1177/1368431019831855.

Tong, C. K., \& Yong, P. K. (1998). Guanxi bases, xinyong and Chinese business networks. British Journal of Sociology, 49(1), 75-96.

Wang, B. X., \& Rowley, C. (2017). Business networks and the emergence of guanxi capitalism in China. In J. Nolan, C. Rowley, \& M. Warner (Eds.), Business networks in east Asian capitalisms: Enduring trends, emerging patterns (pp. 93-118). London: Elsevier.

Wang, M. (2012). South East and South West: Searching for the link between "research regions." In A. Dirlik, G. Li, and H-P. Yen (Eds.), Sociology and anthropology in twentieth-century China (pp. 161-190). Hong Kong: Chinese University Press.

Wank, D. L. (1996). The institutional process of market clientelism: Guanxi and private business in a South China city. The China Quarterly, 147, 820-838.

Wank, D. L. (1999). Commodifying communism: Business, trust and politics in a Chinese city. Cambridge: Cambridge University Press.

Wank, D. L. (2009). Local state takeover in China's private sector: The Yuanhua smuggling case. In T.-W. Ngo (Ed.), Rent seeking in contemporary China (pp. 79-91). London: Routledge.

Weng, Y., \& Xu, H. (2018). How guanxi affects job search outcomes in China? Job match and job turnover. China Economic Review., 51, 70-82.

Whyte, M. K. (2005). Continuity and change in urban Chinese family life. The China Journal, 53, 9-33.

Wu, Y., \& Wall, M. (2019). The ties that bind: How the dominance of WeChat combines with guanxi to inhibit and constrain China's contentious politics. New Media \& Society., 21(8), 1714-1733.

$\mathrm{Wu}$, Y. (1990). The usages of kinship address forms amongst non-kin in mandarin Chinese: The extension of family solidarity. Australian Journal of Linguistics, 10(1), 61-88.

Yan, Y. (1996). The flow of gifts: Reciprocity and social networks in a Chinese village. Stanford, CA: Stanford University Press.

Yang, C. K. (1959). A Chinese village in early communist transition. Cambridge, MA: The MIT Press.

Yang, M. M.-h. (1994). Gifts, favors and banquets: The art of social relationship in China. Ithaca, NY: Cornell University Press.

Publisher's note Springer Nature remains neutral with regard to jurisdictional claims in published maps and institutional affiliations.

Jack Barbalet is Professor of Sociology in the Institute for Humanities and Social Sciences at the Australian Catholic University and concurrently is Visiting Fellow in the Department of Political and Social Change at the Australian National University. Barbalet's research is focused on sociological theory and aspects of social relations and social structure in mainland China. Recent publications include "Primitive Accumulation and Chinese Mirrors," Journal of Classical Sociology (2019) 19(1): 27-42; "Violence and Politics: Reconsidering Weber's 'Politics as a Vocation," Sociology (2020) DOI: https://doi.org/10.1177/0038038519895748, and "The Analysis of Chinese Rural Society: Fei Xiaotong Revisited," Modern China (2020) DOI: https://doi. org/10.1177/0097700419894921. 